University of Nebraska - Lincoln

DigitalCommons@University of Nebraska - Lincoln

Community and Regional Planning Program:

Faculty Scholarly and Creative Activity

Community and Regional Planning Program

2018

\title{
An examination of midwestern US cities' preparedness for climate change and extreme hazards
}

Qiao Hu

Zhenghong Tang

Martha Shulski

Natalie Umphlett

Tarik Abdel-Monem

See next page for additional authors

Follow this and additional works at: https://digitalcommons.unl.edu/arch_crp_facultyschol

Part of the Emergency and Disaster Management Commons, and the Urban, Community and Regional Planning Commons

This Article is brought to you for free and open access by the Community and Regional Planning Program at DigitalCommons@University of Nebraska - Lincoln. It has been accepted for inclusion in Community and Regional Planning Program: Faculty Scholarly and Creative Activity by an authorized administrator of DigitalCommons@University of Nebraska - Lincoln. 
Authors

Qiao Hu, Zhenghong Tang, Martha Shulski, Natalie Umphlett, Tarik Abdel-Monem, and Frank E. Uhlarik 


\title{
An examination of midwestern US cities' preparedness for climate change and extreme hazards
}

\author{
Qiao Hu, ${ }^{1}$ Zhenghong Tang, ${ }^{1}$ Martha Shulski, ${ }^{2}$ \\ Natalie Umphlett, ${ }^{2}$ Tarik Abdel-Monem, ${ }^{3}$ \\ and Frank E. Uhlarik ${ }^{4}$ \\ 1 Community and Regional Planning Program, University of Nebraska-Lincoln, \\ Lincoln, USA \\ 2 School of Natural Resources, University of Nebraska-Lincoln, HARH 153B, \\ UNL, Lincoln 68583-0931, USA \\ 3 Public Policy Center, University of Nebraska-Lincoln, Lincoln, USA \\ 4 City of Lincoln, Nebraska, USA \\ Corresponding author — Martha Shulski, mshulski3@unl.edu
}

\begin{abstract}
The increasing occurrence of extreme weather and climate events raised concerns in regard to hazard mitigation and climate adaptation. Local municipal planning mechanisms play a fundamental role in increasing a community's capacity toward longterm resiliency. This study employs the content analysis method to evaluate the 95 selected cities located in the US Federal Emergency Management Agency Region VII and examine how these local plans, including local comprehensive plans (CPs), hazard mitigation plans (HMPs), and local emergency operations plans (EOPs), prepare communities for climate change and possible extreme events. Results indicate that local plans delineated multiple resources and diverse strategies to reduce community climatic risks, where HMPs have medium-level preparation, and CPs and EOPs have limited level preparation. Local HMPs lead in mitigating for impacts from potential extreme events, but both local CPs and EOPs are proactively adapted for climatic risks. Common strengths and weaknesses exist between different planning mechanisms. Large variations exist among plans due to varying jurisdictions among
\end{abstract}

Published in Natural Hazards 94 (2018), pp 777-800.

doi:10.1007/s11069-018-3420-y

Copyright (C) 2018 Springer Nature B.V. Used by permission.

Submitted 9 March 2018; accepted 25 July 2018; published 2 August 2018. 
cities. However, the plans score similarly overall-higher on strategies and factual base but are short of clear and detailed goals, objectives, and agendas. Finally, despite the diverse vertical and horizontal outreach, there is inadequate integration among local planning mechanisms to share climate hazard information.

Keywords: Climate change, Extreme hazards, Local comprehensive plan, Local hazard mitigation plan, Local emergency operations plan

\section{Introduction}

Climate change affects human society in far-reaching ways. A changing climate leads to cascading effects in the frequency and severity of extreme hazard events, including prolonged periods of heat, heavy precipitation, winter storms, and droughts (Field 2012; USGCRP 2017). Even for weather and climate events that may not be categorized as extreme, risks can still exist when exposure is combined with a high level of community vulnerability (Wisner 2004). Hazard mitigation refers to "the effort to reduce loss of life and property by lessening the impact of disasters" (FEMA 2013a); and climate adaptation emphasizes "the adjustment in natural or human systems to a new or changing environment that exploits beneficial opportunities or moderate negative effects" (Bierbaum et al. 2014). Hazard mitigation and long-term adaptation for climate change are highly connected, with both contributing to climatic risk reduction and resiliency capacity improvement. While mitigation measures are necessary to directly reduce hazard risks, proactive adaptations are always helpful to address future uncertain climatic conditions (USGCRP 2017; Woodruff and Stults 2016). Both hazard mitigation and climate adaptation are suitable for application at local jurisdictional levels, as most societal and economic losses and strategies are place-based (Næss et al. 2005; Laukkonen et al. 2009; Tang et al. 2010; Amundsen et al. 2010; Measham et al. 2011; Picketts et al. 2014; Stevens and Senbel 2017). Moreover, local jurisdictions are the stakeholders directly responsible for implementing those strategies, and also receive any tangible benefits (Brody et al. 2008; Picketts et al. 2014). Despite the importance of local roles, existing efforts toward climatic hazards mainly focus on the national scale and/or are concentrated on large urban areas (Agrawal et al. 2008; Measham et al. 2011; Shi et al. 2016). Climate change is often viewed and reported on as a global, instead 
of local issue, which limits local capabilities in dealing with consequences of climate change and extreme hazards (Urwin and Jordan 2008; Van Aalst et al. 2008; Amundsen et al. 2010).

To date, many efforts have been taken by scholars, planners, and policymakers to examine local preparations for various hazards and effects caused by extreme climates. By evaluating plans of 35 cities across the USA, Wheeler (2008) concluded that local plans failed to address climate change adaptation even if climate-related goals and strategies had been set. Bassett and Shandas (2010) evaluated 20 climate action plans at the municipal level and concluded that climate change adaptations rely significantly on land use and transportation solutions. Tang et al. (2010) examined 40 local climate change action plans and found that most of them reflected unsatisfactory levels of analysis and action despite high levels of awareness. The local climate action plans mainly emphasized greenhouse gas reduction from the built environment, rather than more proactive adaptations. Hamin (2011) concluded that climate change adaptation has been widely accepted as a necessary objective at local levels by examining seven adaptation plans from four countries. Preston et al. (2011) evaluated 57 adaptation plans in the USA, England, and Australia, and found most adaptation plans were still under-developed and failed to build strong adaptive capacity. Baker et al. (2012) evaluated seven local climate adaptation plans in three developed countries and concluded that climate change adaptations were not effectively executed and were difficult to apply at local levels. Stone et al. (2012) evaluated climate change action plans among 50 cities in the USA and concluded that local scale and land use-based strategies were not sufficiently integrated with climate change adaptation strategies. Baynham and Stevens (2014) found that 25 of 39 official community plans in British Columbia, Canada have explicitly addressed climate change mitigation and adaptation issues in their local plans. Geneletti and Zardo (2016) reviewed 14 municipallevel climate change adaptation plans and concluded that their adaptation strategies lacked sufficient considerations of factual context. It should be mentioned that even though numerous studies have aimed at interpreting local adaptation capacities to cope with the consequences of climate change and hazard risks, most of those studies focused on plans with narrow sectoral scopes. 
However, climate change is a complex issue involving various sectors (Field 2012; USGCRP 2017). Shared planning mechanisms between different plan types are believed to be the linchpin for effective adaptations (Laukkonen et al. 2009; Horney et al. 2012; Romsdahl et al. 2013; FEMA 2013a, b), as it makes the planning cycle more efficient and effective (FEMA 2010). To further examine adaptation planning for the consequences of climate change, some pioneers have expanded plan evaluation frameworks to multiple plans having direct or indirect connections to hazard mitigation and the effects of climate change. Tang et al. (2013) evaluated the climate action plans from the 24 coastal states in the USA, and found that they had a medium level of awareness, analysis, and action for extreme climate conditions and disaster preparedness, but hazard mitigation and climate adaptation were not the focus of these state-level climate action plans. Woodruff and Stults (2016) evaluated 44 local climate adaptation plans in different categories and found that implementation was rarely mentioned at local levels even though many strategies had been identified. However, they examined those plans' comprehensive capacities addressing climate change adaptation rather than compared elements between different planning mechanisms. Berke et al. (2015) evaluated four different types of local plans (comprehensive plans, hazard mitigation plans, land use plans, parks and recreation plans) in Washington D.C., and found that local plans usually were not aligned with each other and did not identify vulnerable areas in effective ways. However, they only focused on plans in a single city. Berke et al. (2015) evaluated the networks of plans and vulnerability to hazards and climate change. They also found that many community plans did not fully consider the hazard risks, and some plans have actually increased physical and social vulnerability to hazards in climate change. Horney et al. (2016) evaluated the quality of rural hazard mitigation plans in the southeastern USA and found that overall plan quality was poor. Fu et al. (2017) evaluated the sea level rise adaptation and provided extensive comparisons of climate change adaptation between different types of plans. They concluded that local plans from 15 coastal cities had limited efforts in plan implementation to address the challenge of sea level rise. However, their study focused only on adaptation to sea level rise, which can only occur in coastal areas. Extreme hazard events are common consequences of climate change that may 
happen in any geographic scale, and need multiple planning efforts aligned across various sectors.

Compared to coastal areas, inland areas have received relatively limited attention in studies evaluating the extent of local planning preparedness for climate change and related extreme hazards. To fill this gap, this study establishes 32 indicators to examine and evaluate local plans, including hazard mitigation plans (HMP), comprehensive plans (CP), and emergency operations plans (EOP), to identify the extent of preparation for climate change and related extreme hazard risks. More specifically, two specific research questions are addressed in this study: (1) How well do the local jurisdictions in the FEMA Region VII prepare for the potential risks of climate change and extreme hazard events in local HMPs, local CPs, and local EOPs? and (2) How can local plans be integrated to jointly reduce the risks from climate change and related extreme hazard events?

\section{The role of local plans for extreme hazards}

HMPs outline a jurisdiction's long-term efforts and strategies for mitigating the hazards it faces (FEMA 2011a). Hazard mitigation planning is a process used by multiple levels of government to engage stakeholders, identify hazards and vulnerabilities, and take advantage of a wide range of resources to increase resilience (FEMA 2013c; Berke et al. 2012; Babcock 2013; Lyles et al. 2014; Hu et al. 2018). By integrating extreme hazard events, it demonstrates the commitment of the community to reduce risks raised by climate change. It can also serve as a guide for decision-makers to reduce the social and economic effects of extreme hazard events.

Local CPs are widely accepted as a central and legitimate tool for effective land use management. Most natural hazards are geography based, and have measurable frequency and severity. Including hazard mitigation strategies into local CPs has been recognized as a formal mechanism for advancing hazard mitigation and climate adaptation (FEMA 2013b; Lyles et al. 2014). While some strategies are economically unfriendly, proactive hazard mitigation integration at the very initial stage of land use policy development is more timeefficient and cost-effective than later modifications and improvements 
(FEMA 2013a, b, c). Therefore, land use strategies and planning are always functioning as hazard mitigation and adaptation efforts. However, although land use planning is important for long-term risk reduction, Lyles et al. (2014) have proposed that land use planning for hazard mitigation is still under-utilized relative to its potential.

EOPs are the centerpiece of emergency planning, focusing on postdisaster response and recovery functions. EOPs concentrate on direction and control, warning indications and systems, public notification processes, evacuation, and other actions that must be taken at early stages of emergency response (FEMA 2010). While local EOPs mainly concentrate on delineating roles, responsibilities, and procedures, the plans also typically identify vulnerabilities within communities by including an analysis of potential hazards and risk exposures for disaster situations (FEMA 2013b). EOPs facilitate loss prevention, protection, emergency response, and short-term recovery, establishing a stage for successful long-term recovery that is complimentary to HMPs. Existing plans for hazard mitigation are tied to EOPs since both originate from a hazard-based analysis and share similar component requirements (FEMA 2010).

\section{Research framework}

A planning evaluation is defined as a process to bridge the gap between plan content analysis and what components better plans could or should adopt. It is a theoretical process that identifies weaknesses and strengths by comparing plan contents through an integrated analytical framework (Lyles and Stevens 2014; Woodruff and Stults 2016; Guyadeen 2018). Originating in the 1990s, plan quality evaluation has been widely applied in a variety of planning domains, including hazard mitigation, climate change, sustainable development, environmental protection, and affordable housing (Berke and Godschalk 2009; Tang et al. 2010, 2013; Lyles and Stevens 2014; Woodruff and Stults 2016; Hu et al. 2018). Additionally, plan evaluation reflects different parties' desires to better inform planning practices and develop high-quality plans (Wheeler 2008; Berke and Godschalk 2009).

In this study, a coding protocol (see Table 1) for planning content analysis is employed to evaluate how these three different kinds of 
Hu et al. in Natural Hazards 94 (2018)

Table 1 List of indicators for plan evaluation

\begin{tabular}{|c|c|c|c|}
\hline Components & No. & Topic & Measurable indicator \\
\hline \multirow[t]{5}{*}{ Factual base } & 1.1 & Definition & $\begin{array}{l}\text { Identifies/defines climate change (climate } \\
\text { variability, climate variation, changing } \\
\text { climate) }\end{array}$ \\
\hline & 1.2 & Reliable References & $\begin{array}{l}\text { Cites international, national, or regional } \\
\text { climate change-related assessments from } \\
\text { reliable resources: e.g., IPCC, NCA, } \\
\text { NOAA, NCEI, EPA }\end{array}$ \\
\hline & 1.3 & $\begin{array}{l}\text { Uncertainty } \\
\text { Consideration }\end{array}$ & $\begin{array}{l}\text { Realizes and considers uncertainty among } \\
\text { climate change scenarios and implications } \\
\text { for the planning process }\end{array}$ \\
\hline & 1.4 & Historical Hazard & $\begin{array}{l}\text { Analyzes and prioritizes vulnerabilities by } \\
\text { identifying historical extreme climatic } \\
\text { events (storms, floods, drought, heat } \\
\text { waves, etc.) }\end{array}$ \\
\hline & 1.5 & Potential Impacts & $\begin{array}{l}\text { Assesses the impacts of climate change on } \\
\text { mitigation, preparedness, response, and } \\
\text { recovery operations (existing social, } \\
\text { economic, environmental, or built } \\
\text { infrastructure conditions) }\end{array}$ \\
\hline \multirow[t]{2}{*}{ Goals and objectives } & 2.1 & Overarching Vision & $\begin{array}{l}\text { Includes an overarching vision statement } \\
\text { which establishes an overall image of a } \\
\text { desired future to adapt to climate change } \\
\text { (increase resilience, promote } \\
\text { sustainability). }\end{array}$ \\
\hline & 2.2 & Feasible Agenda & $\begin{array}{l}\text { Includes tangible or quantifiable goals, } \\
\text { objectives, or agendas leading to } \\
\text { reductions in local risk, vulnerabilities, and } \\
\text { hazard loss due to extreme climatic } \\
\text { hazards }\end{array}$ \\
\hline \multirow[t]{4}{*}{$\begin{array}{r}\text { Coordination and } \\
\text { communication }\end{array}$} & 3.1 & $\begin{array}{l}\text { Horizontal } \\
\text { Coordination }\end{array}$ & $\begin{array}{l}\text { Builds horizontal coordination (cross-sector } \\
\text { or multi stakeholder linkages) to adapt to } \\
\text { extreme climatic hazards-States that local } \\
\text { level universities, agencies, nonprofits or } \\
\text { businesses are engaged in this process }\end{array}$ \\
\hline & 3.2 & Vertical Coordination & $\begin{array}{l}\text { Builds vertical coordination } \\
\text { (intergovernmental or multiple } \\
\text { coordination) to adapt to extreme climatic } \\
\text { hazards-States that state or federal level } \\
\text { agencies, nonprofits, or businesses are } \\
\text { engaged in this process }\end{array}$ \\
\hline & 3.3 & Public Engagement & $\begin{array}{l}\text { States how public engagement is integrated } \\
\text { into the planning process and planning } \\
\text { maintenance for policies, projects, and } \\
\text { actions to adapt to extreme climatic } \\
\text { hazards }\end{array}$ \\
\hline & 3.4 & $\begin{array}{l}\text { Integrative Planning } \\
\text { Mechanism }\end{array}$ & $\begin{array}{l}\text { Facilitates integration of hazard mitigation } \\
\text { between different planning mechanisms to } \\
\text { adapt to extreme climatic hazards } \\
\text { (integrates the requirements of the } \\
\text { mitigation plan into other planning } \\
\text { mechanisms when appropriate) }\end{array}$ \\
\hline
\end{tabular}


Hu et al. in Natural hazards 94 (2018)

Table 1 (Continued)

\begin{tabular}{|c|c|c|c|}
\hline Components & No. & Topic & Measurable indicator \\
\hline \multirow[t]{10}{*}{$\begin{array}{l}\text { Policies, tools, } \\
\text { strategies }\end{array}$} & 4.1 & Land Use & $\begin{array}{l}\text { Strengthens land use regulations-land use } \\
\text { strategies focused on preparing for climate } \\
\text { change }\end{array}$ \\
\hline & 4.2 & Building Code & $\begin{array}{l}\text { Adopts and enforces building codes and } \\
\text { design standards to improve physical } \\
\text { infrastructure's resilience to changing } \\
\text { climate }\end{array}$ \\
\hline & 4.3 & Floodplain & $\begin{array}{l}\text { Strengthens floodplain policies and } \\
\text { management, including the National Flood } \\
\text { Insurance Program (includes financing or } \\
\text { insurance strategies to prepare for future } \\
\text { climate change) }\end{array}$ \\
\hline & 4.4 & Clean Energy & $\begin{array}{l}\text { Adopts climate initiatives and clean energy } \\
\text { facilities to reduce greenhouse gas } \\
\text { emissions and to increase investments in } \\
\text { efficiency and renewable energy (wind, } \\
\text { solar, biomass resources, and nuclear } \\
\text { power) }\end{array}$ \\
\hline & 4.5 & Ecosystem & $\begin{array}{l}\text { Restores and maintains intact natural } \\
\text { ecosystems with varied native species, } \\
\text { including prairies, forests, streams, and } \\
\text { wetlands }\end{array}$ \\
\hline & 4.6 & Water Resources & $\begin{array}{l}\text { Establishes and supports water resources } \\
\text { management to ensure water quality and } \\
\text { water supply }\end{array}$ \\
\hline & 4.7 & Green Infrastructure & $\begin{array}{l}\text { Promotes and prioritizes green and natural } \\
\text { infrastructures }\end{array}$ \\
\hline & 4.8 & $\begin{array}{l}\text { Sustainable } \\
\text { Agriculture }\end{array}$ & $\begin{array}{l}\text { Initiates and strengthens agricultural } \\
\text { adaptation to develop and maintain a } \\
\text { sustainable agricultural system }\end{array}$ \\
\hline & 4.9 & Warning System & $\begin{array}{l}\text { Establishes early warning systems to make } \\
\text { effective use of climate change } \\
\text { information }\end{array}$ \\
\hline & 4.10 & Human Health & $\begin{array}{l}\text { Reduces public health risks due to } \\
\text { ecosystem changes, degradation of air } \\
\text { quality, temperature issues, and increased } \\
\text { humidity }\end{array}$ \\
\hline \multirow[t]{3}{*}{ Implementation } & 5.1 & Implementing & $\begin{array}{l}\text { Ability Includes information about agencies } \\
\text { responsible for actions, proposed timeline } \\
\text { and estimated costs, available funding } \\
\text { resources and technical supports for } \\
\text { climate change adaptation }\end{array}$ \\
\hline & 5.2 & Steering Committee & $\begin{array}{l}\text { Establishes climate change assessment and } \\
\text { response steering committee or advisory } \\
\text { committee to coordinate, monitor, and } \\
\text { assess information regarding all aspects of } \\
\text { climate-related hazards and actions }\end{array}$ \\
\hline & 5.3 & Action Plan & $\begin{array}{l}\text { Prioritizes climate change-related projects, } \\
\text { actions, and strategies, or develops a } \\
\text { climate change action plan into the } \\
\text { planning process }\end{array}$ \\
\hline
\end{tabular}


plans (HMPs, CPs, and EOPs) address climate change and extreme hazard events. Five components are included in the coding protocol, including (1) factual base, (2) goals and objectives, (3) coordination and communication, (4) policies, tools, and strategies, and (5) implementation. Factual base specifies and prioritizes key climate-related issues that can correspond to mitigation needs in communities. The factual base can also provide the evidentiary foundation in which policies and planning goals rely on (Tang et al. 2013; Berke et al. 2014; Woodruff and Stults 2016). Five indicators are included in this factual base component: climate change integration, reliable references, uncertainty consideration, hazard identification, and related impacts analysis. Climate change integration has been required by a series of initiatives issued by FEMA as an essential approach to bridge the gap between climate change and natural hazards (FEMA 2010, 2011b). Reliable references associated with local impacts of climate change help local jurisdictions be ready for potential climate change impacts (Snover et al. 2007; USGCRP 2017). The uncertainty of climate change scenarios increases the difficulty in interpreting its potential impacts, which implies the need to better integrate uncertainty into planning (Lempert and Collins 2007; Field 2012). The interpretation of potential climate change impacts helps identify the exposure risks of vulnerable populations and communities (Bierbaum et al. 2013).

Goals and objectives (Table 1) are defined by two indicators, which include overarching vision and feasible agenda. An overarching vision represents the common goals and values a community aspires toward (Berke and Kaiser 2006; Berke and Godschalk 2009), which reflects public recognition of the importance of climate change. Feasible agenda includes tangible, measurable outcomes that facilitate accomplishment of the overarching vision (Berke and Kaiser 2006).

Coordination and communication (Table 1 ) is the process that mobilizes and optimizes available resources to adaptively reduce hazard vulnerability to extreme hazard events. Vertical and horizontal coordination and communication ensure that all strategies are synchronized within the same sequence and scope (FEMA 2010). An integrative planning mechanism increases the opportunities for integration and synchronization, and makes planning cycles and maintenance more efficient and effective (FEMA 2010). Public 
engagement increases the likelihood to implement and finalize the documented strategies (FEMA 2010).

Policies, tools, and strategies (Table 1) provide theoretical and ideal policy foundations to direct decision making and to accomplish plan goals (Moser and Luers 2008; Baker et al. 2012; Tang et al. 2013; Bierbaum et al. 2013; Woodruff and Stults 2016). Ten actions are included in this component. Extreme hazard events exert cascading effects on fields which have closer links to climate and human health, such as water, agriculture, and health (Field 2012; USGCRP 2017). Potential low-regret strategies increase the resiliency of our man-made system in coping with climate change, including enforcement of sustainable land use management, building codes, and floodplain management (Schwab 2010); undertaking new development patterns like green infrastructure and renewable energy (USGCRP 2017); development of watershed management and ecosystem restoration (Field 2012; Gasper et al. 2011); improvement of health surveillance and sanitation (EPA 2015); integration of sustainable agriculture and irrigation systems (Lin 2011); and establishment of early warning systems (Field 2012).

Implementation (Table 1) functions as a process to measure local adaptive ability to translate climate-related policies, tools, and strategies into practical actions (Berke et al. 2012; USGCRP 2017; Woodruff and Stults 2016). Three indicators are specified in this component, including implementing ability, the establishment of a steering committee, and action plan. Cumulative actions and coordination across sectors are the linchpins for a local community to be well prepared for climate change (Snover et al. 2007). Therefore, forming a specific climate change preparedness steering team and action plan for climate change will make mitigation strategies more effective and efficient (Snover et al. 2007).

\section{Research methods}

\subsection{Sample collection and data resources}

The sampling targets in this study are local HMPs, local CPs, and local EOPs. The sampling areas (see Fig. 1) include all municipalities in 


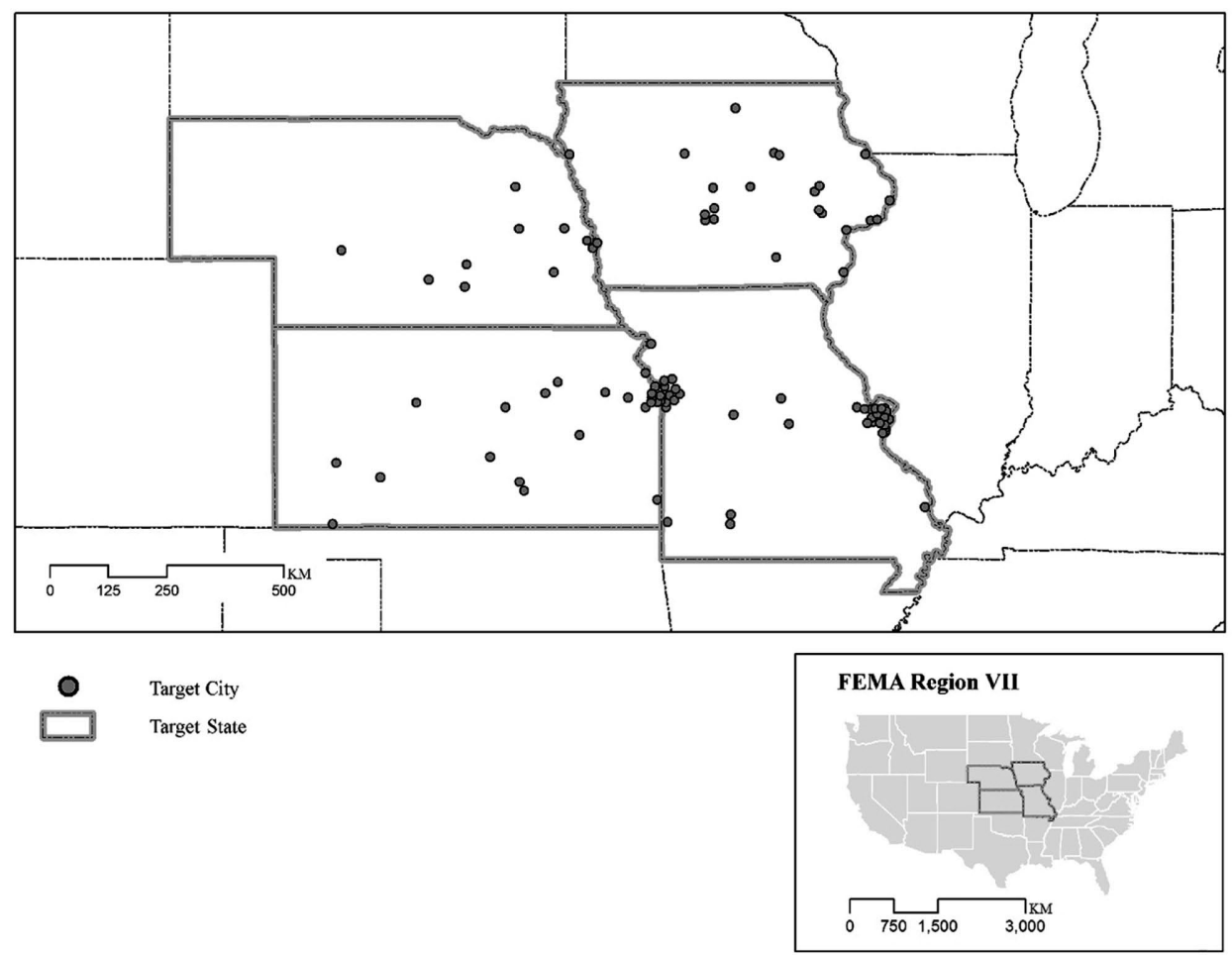

Fig. 1 Cities involved in this research

the four states in the FEMA Region VII (Missouri, lowa, Nebraska, and Kansas) with a population of at least $20,000(n=95)$, as municipalities with a population under 20,000 are unlikely to formulate related plans. Although these municipalities are diverse in size, population, and growth rates, they face similar challenges from climate change and extreme climate hazards, such as flooding or drought. We collected the data from the official websites of each municipal. A webbased search is performed to collect plans from local government websites. A corresponding county plan is used as an alternative when a municipal plan is not available. The available plans reflect the recent conditions and planning policies of local jurisdictions. The CPs were made during 2003-2017. The HMPs have the federal requirements for every 5-year updates, thus, these plans were made during 2012-2017. Most of the EOPs were made during 2008-2017, but two of them were updated in 2004. 


\subsection{Coding protocol and data processing}

A two-point binary scale coding protocol is employed for each indicator in the criteria. A binary scale is applied to the plan evaluation process because climate change adaptation at the local level is still in its infancy in many cases. Every item is standardized on a binary scale with either 0 or 1 , where 0 indicates that the item is not described in a plan at all and 1 indicates the presence of the related information. Table 2 illustrates the scoring equation for each plan's total score, the total score of each plan component, as well as the breadth score for each indicator within the plan components. There are 24 indicators in this paper, including 5 indicators in the factual base, 2 in the objectives and goals, 4 in the coordination, 10 in the policies, and 3 in the implantations. The unitary method employed in this research resulted in a range of $0-24$ points for every single plan ( $0-5$ for the factual base, $0-2$ for the objectives and goals, $0-10$ for the policies, 0-4 for the coordination, and 0-3 for the implementation). Eventually, each plan's total score and component scores are standardized to the range of $0-100$ points (" 0 " as the minimum score, and " 100 " as the possible maximum score).

\subsection{Coding Procedures and Statistical Reliability}

To reduce the subjectivity of plan evaluation procedures, a two-coder team is established, and each coder separately reviews each plan with a well-established uniform coding standard. Compared with the

Table 2 Equation for score calculation during plan evaluation

\begin{tabular}{lll} 
Target & \multicolumn{1}{c}{ Equation } & Notes \\
\hline Plan score & $P S_{j}=\frac{100}{n_{j}} \sum_{i=1}^{n_{j}} I_{i}$ & $\begin{array}{l}P S_{j}=\text { quality of the } j \text { th plan (0-100) } \\
n_{j}=\text { number of components within the } j \text { th plan } \\
\left.I_{i}=\text { represents the } \text { ith indicator's score (ranging } 0-1\right)\end{array}$ \\
Plan component score & $P C S_{j}=\frac{100}{m_{j}} \sum_{i=1}^{m_{j}} I_{i}$ & $\begin{array}{l}P C S_{j}=\text { quality of the } j \text { th plan component }(0-100) \\
m_{j}=\text { number of indicators within the } j \text { th plan component } \\
\left.I_{i}=\text { represents the } \text { ith indicator's score (ranging } 0-1\right)\end{array}$ \\
Indicator breadth score $\quad I B S_{j}=\frac{P_{j}}{N} * 100$ & $\begin{array}{l}P_{j}=\text { the number of plans that address the } j \text { th indicator } \\
N=\text { total number of the plans in the study }\end{array}$
\end{tabular}


method of inter-coder average agreement, Krippendorff's alpha (a) can measure the extent to which the two coders agree on whether the plans contain the proposed indicators in the plan evaluation (Krippendorff 2012; Stevens et al. 2014). In this study, the minimal Krippendorff's alpha (a) is 0.75 and the overall average Krippendorff's alpha (a) is above 0.80 . Both of the results indicate sufficient reliability based on the literature by Stevens et al. (2014).

\section{Results}

\subsection{Adoption of Related Plans}

Initially, a total of $76 \mathrm{CPs}, 61 \mathrm{HMPs}$, and 50 EOPs are collected (see Table 3). However, only 35 out of 61 HMPs and 42 out of 50 EOPs are valid, as some cities or counties are sharing identical plans or have joint plans. This brings the total number of plans for plan evaluation to 153 . Each collected plan represents the most recently available version in the local jurisdictions. Table 3 provides an overview of the types of plans collected for each state in the study region.

\subsection{Overall plan quality scores}

Overall, plan quality scores are low (see Figs. 2, 3, Table 4), with the mean of total plans roughly one-third of the full score $(\mathrm{M}=35.7$, at a scale $0-100$ ). Approximately $50 \%$ of plans score between 25.0 (First quartile) points to 45.8 (Third quartile), and 50\% score below 37.5

Table 3 Collected plans from the four states

\begin{tabular}{lccccc} 
State & $n=$ & $\begin{array}{c}\text { Local } \\
\text { comprehensive } \\
\text { plans } \\
\text { (percentage) }\end{array}$ & $\begin{array}{c}\text { Local hazard } \\
\text { mitigation } \\
\text { plans } \\
\text { (percentage) }\end{array}$ & $\begin{array}{c}\text { Local emergency } \\
\text { operations } \\
\text { plans } \\
\text { (percentage) }\end{array}$ & All plans \\
\hline Missouri & 35 & 28 & 8 & 13 & $49(32)$ \\
lowa & 23 & 21 & 12 & 4 & $37(24)$ \\
Nebraska & 12 & 10 & 7 & 12 & $29(19)$ \\
Kansas & 25 & 17 & 8 & 13 & $38(25)$ \\
Total & 95 & $76(50 \%)$ & $35(23 \%)$ & $42(27 \%)$ & $153(100)$ \\
\hline
\end{tabular}




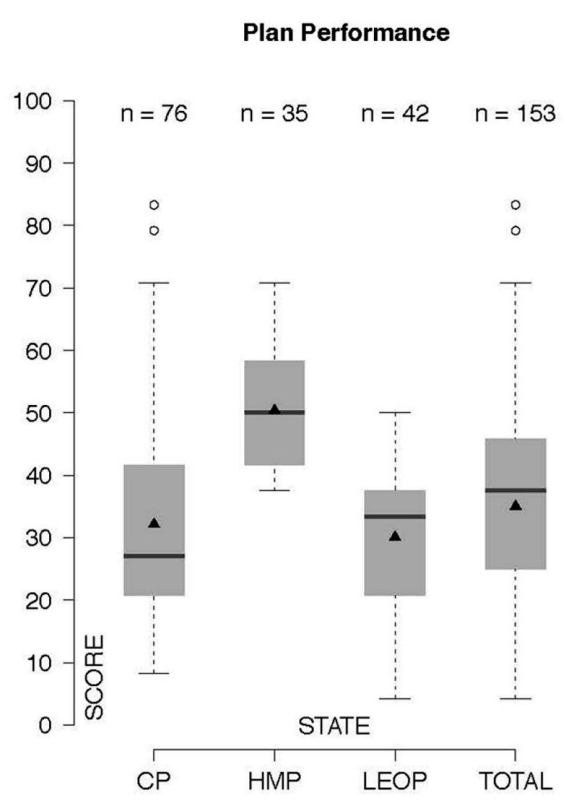

Comprehensive Plan Performance

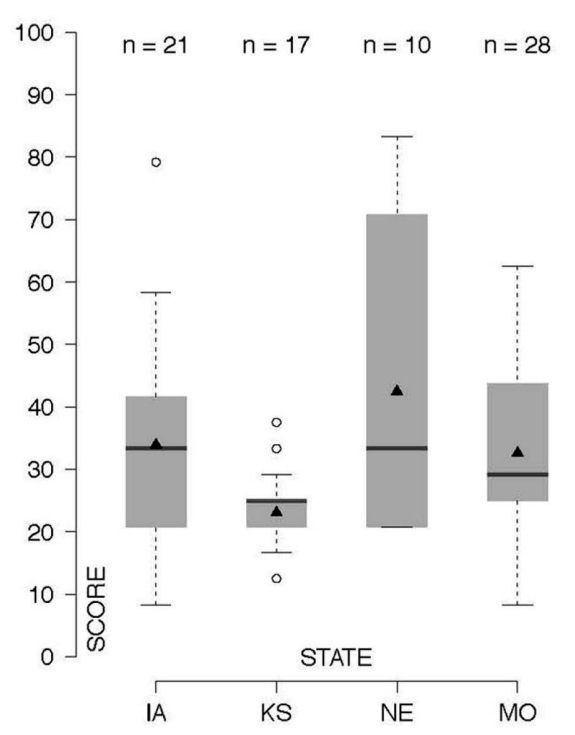

Hazard Mitigation Plan Performance

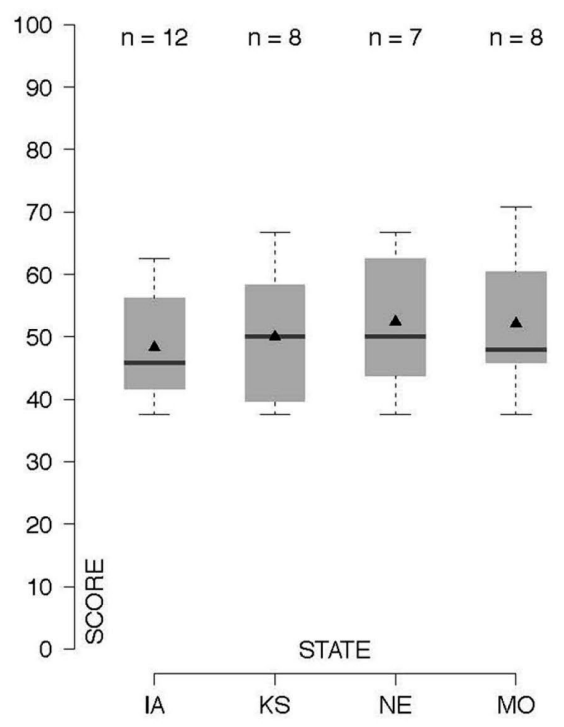

Emergency Operations Plan Performance

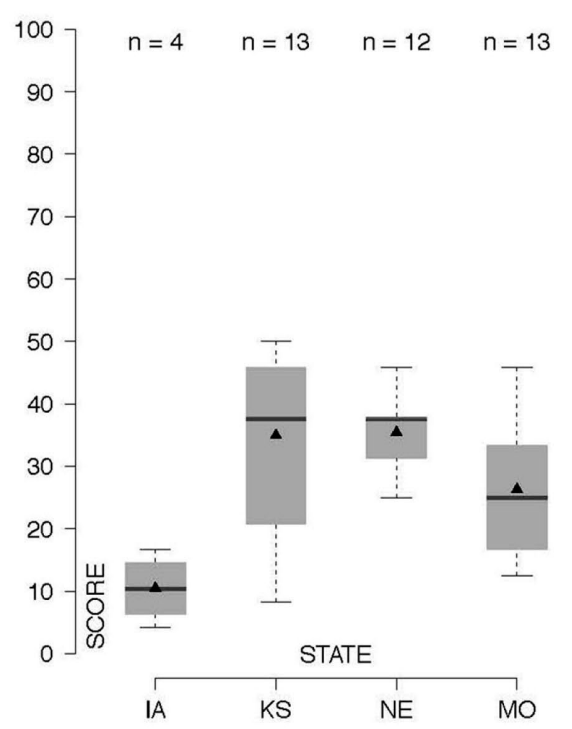

Fig. 2 Plan performance by different planning mechanisms. ${ }^{*}$ The " $\boldsymbol{\Delta}$ " represents the mean of corresponding plan group; the "-" represents the median of corresponding plan group; " $n$ " represents the sample population of corresponding plan group

(Median). In addition, large variations in quality scores exist among the plans, with a range of 79.1 (Min = 4.2, Max = 83.3). Only two out of the 153 plans receive relatively high scores, and are displayed as outliers in Fig. 2-Cedar Rapids, IA (Score $=79.2)$ and Omaha, NE (Score $=83.3$. 


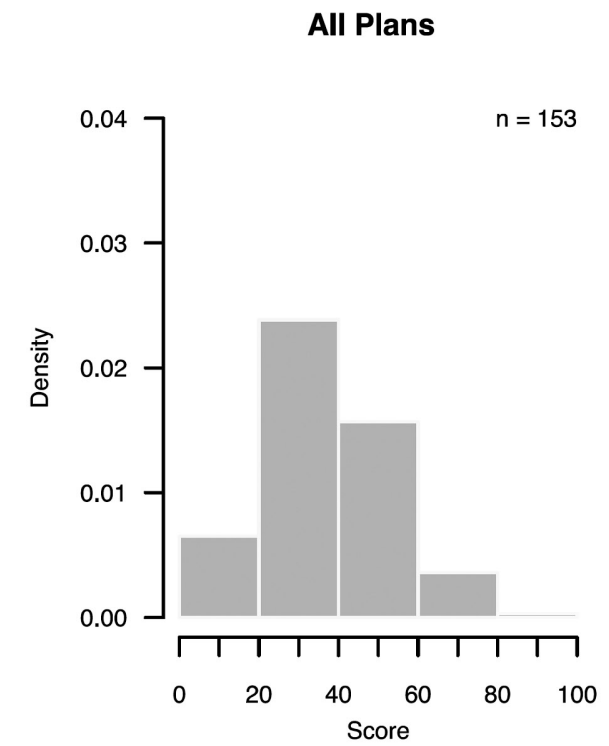

Hazard Mitigation Plan

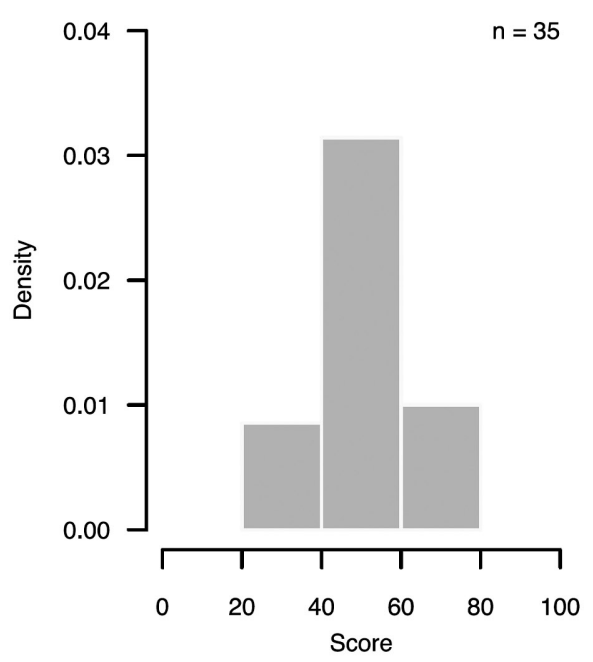

Local Emergency Operations Plan

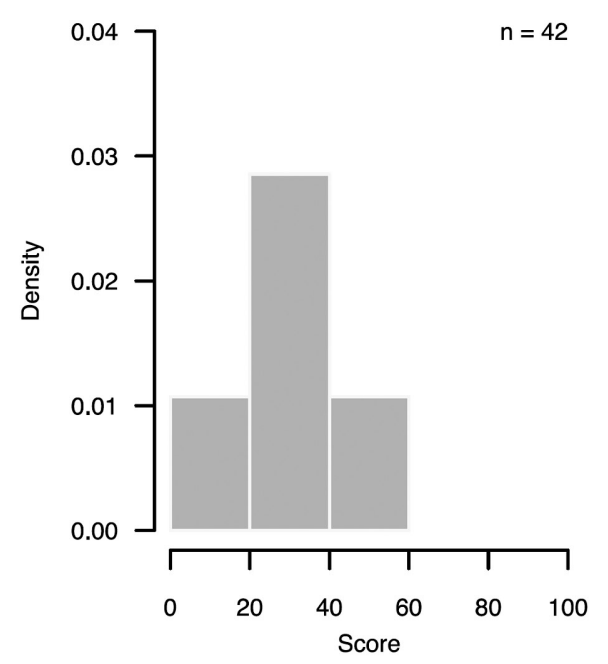

Comprehensive Plan

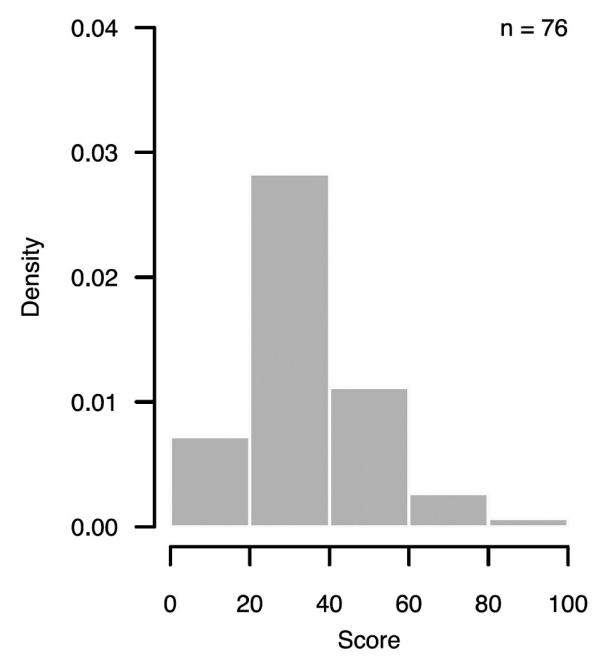

Fig. 3 Score distribution for different types of plans. *The "Density" represents the Density = Proportion/ Width; Class proportion = Frequency/n; the " $n$ " represents the sample population of corresponding plan group

Table 4 Overview description of plan scores

\begin{tabular}{lrrrrrrr} 
Type & $\begin{array}{c}\text { Number } \\
\text { of plans }\end{array}$ & Min. & Max. & Range & Mean & SD Median \\
\hline Local comprehensive plans & 76 & 8.3 & 83.3 & 75.0 & 32.12 & 15.84 & 27.10 \\
Local hazard mitigation plans & 35 & 37.5 & 70.8 & 33.3 & 50.35 & 9.87 & 50.00 \\
Local emergency operations plans & 42 & 4.2 & 50.0 & 45.8 & 30.05 & 12.08 & 33.30 \\
All plans & 153 & 4.2 & 83.3 & 79.1 & 35.70 & 15.80 & 37.50 \\
\hline
\end{tabular}


The overall plan quality for the CPs we examined is very weak. The mean for $C P s$ is less than one-third of the full score $(M=32.1)$. Additionally, 50\% of CPs have a score between 20.8 (First quartile) to 41.7 (Third quartile), and 50\% of plans score below 27.1 (Median). Large variation also exists among the CPs, and their performance scores range from very low ( $\mathrm{Min}=8.3$ ) to medium-high ( $\mathrm{Max}=83.3$ ). The two outliers displayed in Fig. 2 are again Cedar Rapids, IA (Score = 79.2) and Omaha, NE (Score $=83.3$ ). They also receive the first and second highest scores among all plans (including CPs, HMPs, EOPs). Compared with other plans, CPs have the largest range, largest deviation ( $S D=15.84)$, the highest max score, and the lowest average score.

The overall plan quality for the HMPs we examined is higher, demonstrating midrange performance under our criteria. The mean score is almost one-half of the full score $(\mathrm{M}=50.35)$. Approximately $50 \%$ of the plans scored between 41.7 (First quartile) to 58.3 (Third quartile), and $50 \%$ of plans scored below 50.0 (Median). Relatively smaller variation exists among the hazard mitigation plans, as their performance scores range from 37.5 (Min) to 70.8 (Max). Compared with the other plan types, the HMPs have the smallest range, lowest deviation (SD $=15.84)$, highest mean score and the highest median score. Thus, the HMPs are relatively better equipped to address climatic hazards than the other types of plans we investigated.

On the other hand, the total plan quality for local EOPs is quite weak. The total EOP mean is less than one-third of the full score (M $=30.05$ ). $50 \%$ of the plans score from 20.80 (First quartile) to 37.50 (Third quartile), and 50\% score below 37.5 (Median). There are also some significant variations among scores, as their performance range from 4.2 (Min.) to 50.0 (Max). Compared with the other plan types we examined, local EOPs have the lowest minimum score, lowest mean value, and mid-level deviation.

For the 23 jurisdictions with all three types of plans (CPs, HMPs, and EOPs), the overall mean score is 41.00 which is slightly higher than the mean score of 35.70 from all 95 jurisdictions. In these 23 jurisdictions with all three types of plans, the mean scores reach 33.70, 55.07, and 34.20 for CPs, HMPs, and EOPs, which is also slightly higher than their previous mean score of $32.12,50.35$, and 30.05 , respectively. 
Table $\mathbf{5}$ Score description by states and plan types

State Local comprehensive plan Local hazard mitigation plan Local emergency operations plan

\begin{tabular}{|c|c|c|c|c|c|c|c|c|c|c|c|c|c|c|c|}
\hline & $N$ & Mean & $S D$ & Min & Max & $N$ & Mean & $S D$ & Min & Max & $N$ & Mean & $S D$ & Min & Max \\
\hline lowa & 21 & 33.93 & 16.90 & 8.3 & 79.2 & 12 & 48.26 & 8.03 & 37.5 & 62.5 & 4 & 10.43 & 5.38 & 4.2 & 16.7 \\
\hline Kansas & 17 & 23.04 & 7.08 & 12.5 & 37.5 & 8 & 50.00 & 10.68 & 37.5 & 66.7 & 13 & 34.92 & 12.91 & 8.3 & 50.0 \\
\hline Nebraska & 10 & 42.48 & 24.27 & 20.8 & 83.3 & 7 & 52.39 & 12.00 & 37.5 & 66.7 & 12 & 35.42 & 5.75 & 25.0 & 45.8 \\
\hline Missouri & 28 & 32.59 & 12.83 & 8.3 & 62.5 & 8 & 52.06 & 10.91 & 37.5 & 70.8 & 13 & 26.28 & 9.81 & 12.5 & 45.8 \\
\hline
\end{tabular}

\subsection{State performance}

By state, Nebraska receives the highest overall scores for each plan type (see Table 5), including CPs $(M=42.48)$, HMPs $(M=52.06)$, and EOPs ( $M=35.42)$. lowa receives the lowest score on HMPs $(M=48.26)$ and local EOPs $(M=10.43)$, but this could be because only four local EOPs are collected for the entire state. Meanwhile, Kansas receives the lowest score on CPs $(M=23.93)$. By plan type, consistent with overall plan quality scores, HMPs receive the highest values in every state, with points evenly distributed across the states (3.8 difference). Medium-high variation exists in the CPs (Range $=10.9)$ and the local EOPs (Range $=15.0$ ).

\subsection{Category and indicator performance}

We find that for each type of plan we examined, in general, the plans lack consistent scoring results across plan component categories. Plans receive relatively high scores (see Table 6, Fig. 4) on the "policies, tools, strategies" category ( $M=49.67)$ and the coordination and communication category $(M=47.13)$. However, low scores occur in

Table 6 Score description by plan components

\begin{tabular}{lrrrrrrr} 
Categories & CP & \multicolumn{3}{c}{ HMP } & & LEOP & \multicolumn{2}{c}{ All plans } \\
& Mean & SD & Mean & SD & Mean & SD & Mean \\
\hline Factual base & 17.40 & 21.85 & 57.14 & 24.80 & 25.24 & 15.96 & 28.65 \\
Goals and objectives & 6.49 & 21.99 & 0.00 & 0.00 & 0.00 & 0.00 & 3.22 \\
Coordination and communication & 38.64 & 35.25 & 60.71 & 38.96 & 51.19 & 36.19 & 47.13 \\
Policies, tools and strategies & 49.87 & 22.57 & 62.00 & 11.83 & 39.05 & 19.10 & 49.67 \\
Implementation & 2.60 & 12.98 & 19.98 & 16.55 & 0.00 & 0.00 & 5.86 \\
& & & & & & & \\
\hline
\end{tabular}




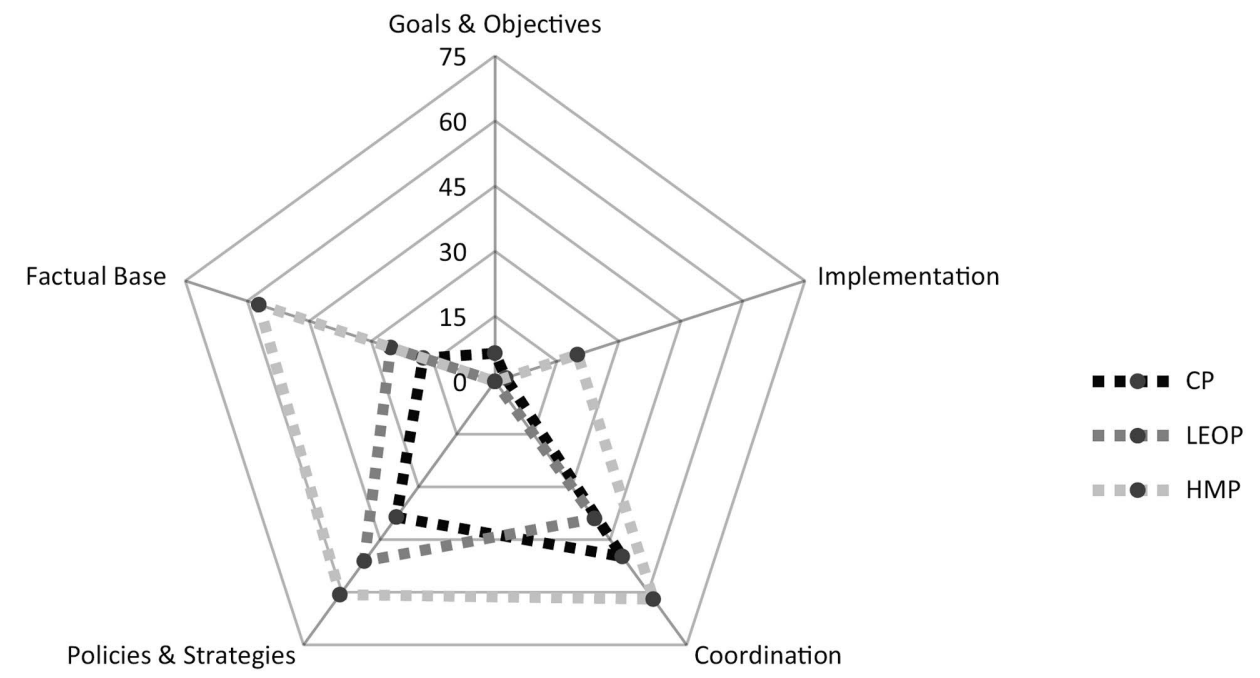

Fig. 4 Category performance by plan types

the factual base category ( $M=28.64)$ and there is very low performance in the goals and objectives $(M=3.22)$ and implementation categories $(M=5.86)$. Thus, even though the policies, tools, strategies and coordination and communication categories receive relatively high scores, it does not mean that they result in plans with high capacities for adaptive actions.

The factual base category scores highest on the HMPs ( $M=57.1)$, indicating that hazard mitigation plans focus content on preparedness for extreme hazard events. The local EOPs ( $M=25.2)$ and CPs $(M=17.4)$ receive a similar score. However, the overall score for the factual base component is very weak. This is concerning because the factual base component provides the empirical foundation for identifying key hazards and forming fundamental policies and approaches toward those hazards. Insufficient data can jeopardize an authority's ability to predict and prepare for future unknown extreme hazard events, and also erode the connection between policy development and plan implementation. Consistent with other findings, the HMPs are well prepared in almost every factual base indicator (see Fig. 5) compared with other plan types, especially in including credible references (breadth $=0.91$ ) and extreme hazard events identification (breadth $=0.97$ ). The CPs receive 0.26 in including credible references. This is a similar score but a little lower than the local EOPs (breadth = 0.36 ), and 0.43 in extreme hazard events identification, which is also 

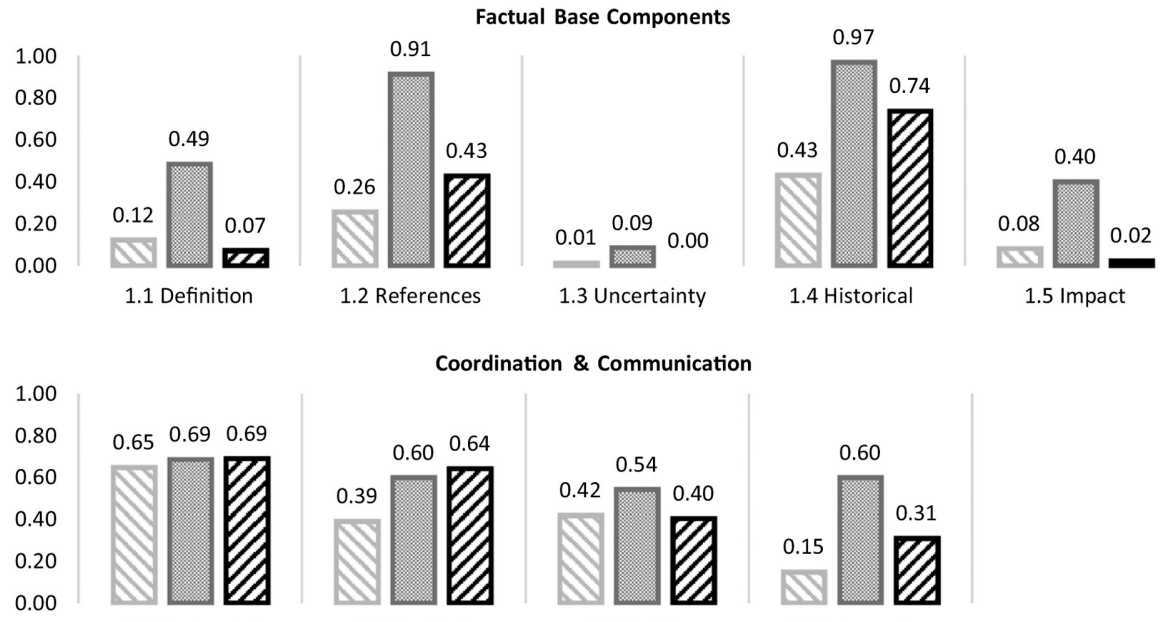

Coordination \& Communication
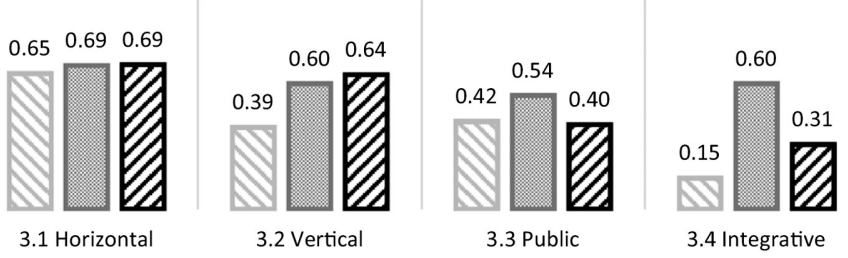

1.00

3.2 Vertical

3.3 Public

3.4 Integrative

Goals \& Objectives

0.80

0.60

0.40

0.20

$\begin{array}{lll}0.09 & 0.00 & 0.00\end{array}$

$\begin{array}{lll}0.04 & 0.00 \quad 0.00\end{array}$

2.1 Vision

2.2 Agenda

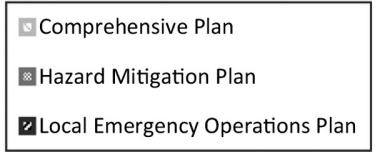

Policies, Tools \& Strategies
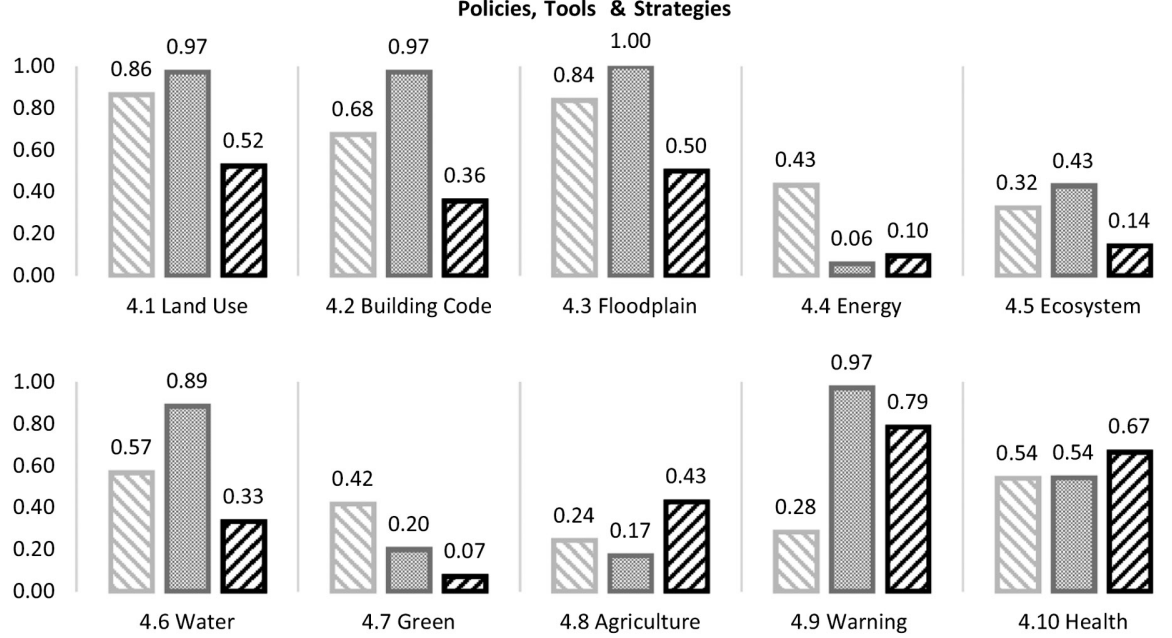

4.9 Warning

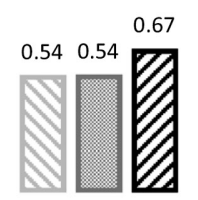

4.10 Health
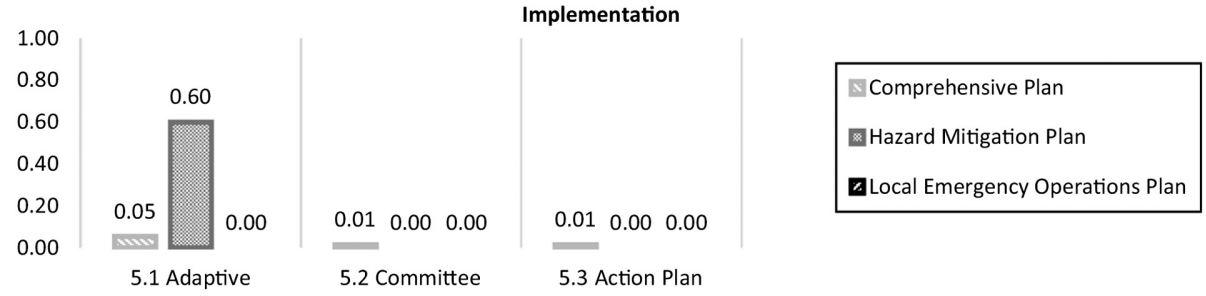

Fig. 5 Indicator performance by plan components 
lower than the local EOPs (breath $=0.61$ ). In defining climate change and analyzing related hazard impacts, the HMPs still occupy the top position: 0.49 for defining climate change and 0.40 for analyzing related hazard impacts. Meanwhile, the CPs receive very low scores on climate change definition (breadth $=0.12$ ), similar to the local EOPs (breadth $=0.10$ ), and also extremely low scores in analyzing related hazard impacts (breadth $=0.08$ ), but higher than the local EOPs (breadth $=0.02$ ). Despite the variation of the performance among the various indicators in the factual base category, all three plan types receive a very low score in climate change uncertainty consideration: 0.09 for the HMP, 0.01 for the CPs, and 0.00 for the local EOPs.

Goals and objectives score the lowest among the five plan component categories in this study. Only a few CPs mention climate changerelated extremes in their plan goals and objectives. None of the local EOPs and the HMPs refers to it in their plan goals and objectives. This implies that insufficient attention is paid to integrating climatic extremes into short or long-term scenarios. This may be because the subtle, invisible, but chronic effects of climatic extremes make it hard for the general public to connect the factual base to climatic extremes. Among the two indicators in this category, very few comprehensive plans establish an overarching vision to adapt to climate change (breath $=0.09$ ), and there is a similarly low score in tangible or quantifiable goals, objectives or agendas to address extreme hazard events (breadth $=0.04$ ). Neither the local HMPs nor the local EOPs mention overarching vision and quantifiable agendas.

HMPs receive the highest score for coordination and communication ( $M=62.0)$, indicating that the HMPs better facilitate interaction with diverse sectors, agencies and organizations than the CPs (M = 49.9) and the local EOPs $(M=39.0)$. Among specific indicators, the three plan types score similar performance levels in horizontal coordination: CPs (breadth $=0.65$ ), local EOPs (breadth $=0.62$ ), and HMPs (breadth $=0.69$ ). For vertical coordination, the HMPs retain the highest position (breadth $=0.60$ ), the local EOPs are second (breadth $=$ 0.54 ), while the CPs receive the lowest score (breadth $=0.39$ ). For public involvement, the local HMPs are still the best performer (breadth $=0.54$ ), while the CPs (breadth $=0.42$ ) and the local EOPs (breadth = 0.43 ) receive similar but lower performance levels. Finally, the indicator of establishing an integrative planning mechanism is well-established 
in the local HMPs (breadth $=0.60$ ), but clearly lower than the CPs (breadth $=0.15$ ) and the local EOPs (breadth $=0.30$ ).

Policies, tools, and strategies receive the highest score on the HMPs $(M=60.7)$. The local EOPs score slightly lower than the HMPs ( $M=$ 51.2), and the CPs receive the lowest mean score for this component $(M=38.6)$. This finding is consistent with the conceptual role of each plan type: HMPs aim to reduce or prevent losses to property and life predisaster as a long-term goal; local EOPs address immediate response and recovery functions in the very initial stages after a disaster, and CPs focus on land use management and planning. Therefore, it is reasonable to expect that local HMPs and EOPs include more strategies to address related hazards. However, despite the variations among the different plan types, the overall scores for policies, tools, and strategies are weak, and even the existing policies we find in plan contents are barely related to climatic extremes and events. This is troublesome, as poorly developed strategies are less likely to enable a city to execute effective agendas for long-term mitigation. The highest scoring indicators among the HMPs are strengthening land use (breadth $=0.97$ ), building code (breadth $=0.97$ ), floodplain management (breadth $=1.00)$, watershed management $($ breadth $=$ 0.89 ), and warning system (breadth $=0.97$ ). Among the three plan types, there is weaker performance among the CPs (breadth $=0.57$ ) and the local EOPs (breadth $=0.27$ ). The highest scoring indicators in the local EOPs are land use (breadth $=0.86$ ), floodplain management (breadth $=0.84)$, and building code (breadth $=0.68$ ). The highest scoring indicators in the local EOPs are warning system (breadth $=0.70$ ), whereas the CPs received an extremely low score (breadth $=0.28$ ). The local EOPs are weak in land use (breadth $=0.57$ ), building code (breadth $=0.33$ ), and floodplain management (breadth $=0.41$ ) fields, whereas the local HMPs and the local CPs typically have some consistent strengths. Interestingly, human health receives a similar score on the local CPs (breadth $=0.54$ ), local EOPs (breadth $=0.56$ ), and the local HMPs (breadth $=0.54$ ). Despite the common strengths or scoring on some indicators, the three plan types also have some common weaknesses on green energy, natural ecosystem, green infrastructure, and sustainable agriculture. While the CPs (breadth $=0.43$ ) are stronger in green energy, the local EOPs (breadth $=0.08$ ) and local HMPs (breadth $=0.06$ ) are extremely low. The local CPs (breadth $=0.32$ ) and 
the local HMPs (breadth $=0.43$ ) are stronger on natural ecosystem than the local EOPs (breadth $=0.12$ ). The local CPs (breadth $=0.42$ ) are also stronger in green infrastructure, but the local EOPs (breadth $=0.06$ ) and the local HMPs (breadth $=0.20$ ) score extremely low. The local EOPs (breadth $=0.36$ ) are stronger than the local CPs (breadth = 0.24 ) and the local HMPs (breadth $=0.17$ ) on sustainable agriculture.

Implementation scores extremely low among the three plan categories. On a scale of $0-100$, HMPs score 20.0 points, while CPs only receive 2.6 points. The local EOPs do not include any content related to implementation. This is concerning as plan implementation and monitoring are the last, but most pivotal step, in the whole planning process. Among the three plans, the local HMPs (breadth $=0.60$ ) build stronger adaptive ability, which is much higher than the CPs (breadth $=0.05$ ) and local EOPs (breadth $=0.00$ ). Only some CPs take actions to construct a steering committee (breadth $=0.01$ ) and create a climate action plan (breadth $=0.01$ ), but the scores are very low.

\section{Discussions}

The findings of this study show that local HMPs play a leadership role in identifying and understanding local hazard vulnerabilities and proposing reasonable measures to mitigate or adapt to risks. According to our scoring criteria, HMPs have a medium level of quality in extreme hazard mitigation and climate adaptation. HMPs offer more stable and comprehensive considerations for extreme hazard events than the CPs and local EOPs. Of course, HMPs are always designed to facilitate long-term approaches to cope with hazards that local jurisdictions may face, while local EOPs focus on immediate post-disaster response, and local CPs concentrate on land use policies and regulations. Therefore, it is reasonable to expect that HMPs contain more evidence-based information and empirical analyses related to extremes hazard events, especially the potential negative impacts of climate change. However, this exposes the issue that there is less synchronizing and coordinating among different public sectors and planning processes.

Not surprisingly, large variations exist among plans across different jurisdictions. These findings are consistent with many previous

plan evaluation studies where low plan quality was found with a large 
variation in geography (Tang et al. 2013; Horney et al. 2016; Woodruff and Stults 2016; Guyadeen 2018). Since adaptation planning for climate change is a recently emerging concept and is highly tied to local context, less clear procedures and specific guidelines have been established to assist local governments (FEMA 2010; Babcock 2013; Shi et al. 2015; Woodruff and Stults 2016). Because current policies initiated at state and federal levels are not strong enough to direct local climate adaptation planning (Berke et al. 2015; Shi et al. 2016), less systematic adaptation approaches have occurred at the local level, resulting in weaker performance levels and large variation (Amundsen et al. 2010; Woodruff and Stults 2016). Although large variations are found among the comprehensive plans, the stability among hazard mitigation plans in this study is a good sign for the emerging and increasing consideration of climate change and extreme hazards in land use planning.

The findings of this study are also consistent with many previous plan evaluation studies where plans scored higher on strategies and factual base, but are short on clear and detailed goals, objectives, and agendas to translate documented policies into on the ground actions (Wheeler 2008; Preston et al. 2011; Baker et al. 2012; Horney et al. 2012; Tang et al. 2013, Baynham and Stevens 2014; Berke et al. 2015; Horney et al. 2016; Stevens and Woodruff and Stults 2016; Stevens and Senbel 2017; Hu et al. 2018; Guyadeen 2018). Despite the relative gaps between different categories, none of the performance levels in those categories indicates a very high level of plan quality. Even though a definition of climate change is often lacking in plans, many plans do contain content aimed at reducing risks from extreme hazards and climate change based on past empirical experiences. The weak performance ratings on objective compounded with a lack of specific procedures for implementation may be due to subtle, elusive, and unpredictable understandings of the effects of climate change on real life (Field 2012; USGCRP 2017). The difficulty to forecast or identify the specific effects of climate change and extreme hazard events may discourage planning officials' motivations to align long-term objectives and goals to adaptation to extreme hazard events.

This research result also supports Guyadeen's (2018) finding that clear and enforceable policies were crucial for a high-quality plan. Overall, the HMPs in the four Midwest states prepared better than CPs and EOPs for extreme hazards and climate risks. But as for the 
goals and objectives, although the CPs perform better than EOPs and HMPs, the quality of goals and objectives for three types of plans still stays in the very low levels. In general, CPs are more comprehensive and strategic, as it is designed to delineate a community's overall direction of development that local land use strategies and regulations are required to follow (FEMA 2013b). The HMPs and EOPs normally specify on issues of hazards risks and emergency procedures. CPs may include an overarching vision statement or/and tangible or quantifiable goals to address climate change, resilience, and sustainability. HMPs and EOPs are generally more operational and hazard specific, and may not consider climate change risks. However, the long-term strategic visions for uncertain climate change and risks are still weakly identified in all three types of plans.

The findings of this study also suggest that there is inadequate integration of the three types of plans for extreme hazard mitigation and long-term climate adaptation. Obvious gaps still exist because each plan is organized by a specific local authority or sector. This is partially consistent with the conclusion of Stone et al. (2012) that local scale and land usebased strategies are less integrated with climate change adaptation at the local level. Interagency coordination channels do exist but historically have been relatively restricted to emergency response conditions. Consistent with Geneletti and Zardo (2016), this study verifies that local level climate change adaptation lacks serious consideration of factual base. Although HMPs reach medium levels of preparation for climate and hazard risks, both CPs and EOPs do not pay too much attention to hazard risk reduction and climate adaptation. Our results also show that climate data and hazard history are generally absent from local EOPs and CPs and some of the HMPs.

The research contributed to the hazard literature through a more thorough assessment for multiple types of local plans. This paper identified the current gaps and opportunities of local planning system (CPs, HMPs, and EOPs) in preparing for climatic hazards. Our research findings contributed to the literature on climate change mitigation and adaptations in inland areas. Compared to coastal justifications, the inland jurisdictions in this study have relatively lower awareness and planning preparation for climate change and extreme hazards. Baynham and Stevens (2014) identified that coastal jurisdictions in British 
Columbia, Canada have more planning policies to mitigate and adapt climate change and potential risks. The findings in this study further support that rural/inland communities had limited preparation for extreme hazards (Horney et al. 2016).

\subsection{Policy recommendations}

In order to improve local planning capacity to address future uncertain climate change and extreme hazard events, this study provides the following policy recommendations.

Incorporate climatic risk information into local plans This study shows that a shared hazard information pattern is absent from the planning cycle. Local plans generally fail to adopt detailed and indepth climatic information related to risk areas despite the numerous climate hazard databases that exist at the federal and state levels. There are a variety of offices and agencies in the USA identified as boundary organizations and provide climate services to clients and stakeholders. Examples include state and federally run organizations (University Extension, State Climate Offices, Regional Climate Centers, Regional Integrated Sciences and Assessments) as well as private industries and consulting firms. A shared sense of potential hazard risks that are collectively faced by different sectors and parties is beneficial for establishing advanced emergency preparedness and responses (Rumore et al. 2016), which in turn sets a good foundation for successful long-term resiliency. Stevens and Senbel (2017) also suggested that a detailed inventory of factual information regarding local climate risk and vulnerability is an important approach to improve local planning capacity for climate change. Hazard datasets, climatic information, and risk assessment maps should be integrated into the section of the plan that addresses areas subject to natural hazards so that HMPs can be coordinated and synchronized with other plans to use the same language.

Develop multiple-win tools, policies, and strategies to achieve community resiliency This study finds that most mitigation strategies in different types of plans are designed around their objectives and scopes. CPs enhance the likelihood of implementing mitigation actions, as they delineate a community's overall direction of development that local land use strategies and regulations are required to 
follow (FEMA 2013b). Collaboration between emergency management strategies and CPs can advance hazard mitigation through the process of forming land use policies and regulations. Additionally, the land use component in a comprehensive plan is not the only area of overlap that implicates emergency management (FEMA 2013b). For example, acquisition or preservation of high hazard areas for recreation, open space, environmental plan, and floodplain management can also be regarded as potential chances for integration, as those areas may function as buffer zones helping to mitigate hazards (FEMA 2013b).

Move from planning to implementation actions The study shows that a holistic mechanism to monitor strategy implementation, maintenance, reviews, and updates is seriously missing in the current planning cycle. However, the absence of existing valid monitoring and maintenance mechanisms may provide an opportune chance to discover gaps and overlapping areas in current planning cycles. Revising local HMPs, EOPs, and CPs are a continuing process. HMPs are often reviewed and revised once every 5 years, CPs are often revised every 5-10 years, while local EOPs are often reviewed on an annual basis. The recurring cycle of plan revisions should provide opportunities for coordinated alignment between HMPs, CPs, and local EOPs, rather than being reviewed or revised once every 5 years.

Establish an integrated planning mechanism to jointly address hazard mitigation and climate adaptation This study suggests that most of the plans are not sufficiently integrated to address hazard mitigation, even though coordination and collaboration components may show a well-developed cooperative planning mechanism. HMPs are essentially drafted as stand-alone plans, and it is relatively uncommon for them to be directly linked or integrated with other community-specific planning tools such as comprehensive land use plans, and other functional plans. The benefits of an integrated planning mechanism among a broad range of plans can be addressed in political and functional dimensions. Politically, an integration mechanism makes planning cycles more time-efficient and cost-effective by ensuring that the sequence and scope of an operation are synchronized in the same step (FEMA 2010). Functionally, an integration mechanism increases opportunities and likelihood for building strong hazard resiliency when it relates to some functional plans (FEMA 2013). The creation of a joint committee will be critical to find the overlapping areas between different planning processes, indicate the deficiencies 
that exist, and execute remedial actions according to an integration agenda. Through synchronized and recurring reviews, the joint committee's agenda would aim to update the coordination of various planning processes in order to jointly address hazard mitigation and climate adaptation. By expanding the scope from synchronized reviews to synchronized climatic risk information and then to synchronized tools, policies, and strategies, the committee would be on a trajectory to build a long-term integrated planning mechanism to address hazards due to climate change and extremes. Based on the findings of this research, we suggest the integrated planning approach for planners and hazard managers to mitigate and adapt extreme climatic risks through existing local planning framework, such as CPs, HMPs, and EOPs. The integrated planning platform helps promote information sharing, build mutual trust, bridge policy gaps, improve policy implementation, and develop capability for local agencies in preparing for future uncertain climatic hazards.

\section{Conclusions}

This study evaluates 153 local plans (CPs, HMPs, and EOPs) from 95 cities with a population over 20,000 in the FEMA Region VII. We examine these plans for content indicating current preparedness and levels of planning integration for climate change and extreme hazard events. We find that existing HMPs have a medium level of preparation, but lead the way in terms of planning for extreme hazards and climate change risks. Local CPs and EOPs are less prepared for these risks. Meanwhile, even though large variations exist among plans based on different jurisdictions, plans generally score higher on strategies and factual base, but are short of clear, detailed goals, objectives, and agendas. Finally, there is inadequate integration among local planning mechanisms to share climate hazard information. These findings can serve as a valuable reference for emergency managers, planners, and policy makers to direct or conduct further research and actions in coping with extreme hazardous events.

However, this study is an initial phase of research into local planning and preparation for extreme hazard risk management, particularly in inland communities. This study only focuses on local CPs, HMPs and EOPs in FEMA Region VII. This study was only able to 
collect limited plans due to the plan accessibility. Many EOPs were not publically accessible and thus did not be used for this study. The constantly increasing movements of mainstreaming hazard mitigation and climate change into different types of plans imply that there will be more and more local plans addressing hazard mitigation integration and climate change adaptation. Also, this study examines how plan quality varied among different planning documents across different local communities, instead of why certain types of plans or certain communities engage in extreme hazard events planning while others do not. Further research studies could include an investigation into the factors motivating extreme hazardous event management at the local level, and what adaptation strategies are translated into realistic actions, and why.

Acknowledgements This paper is funded by the National Oceanic and Atmospheric Administration (NOAA) (Award Number: NA16OAR4210123). The contents do not necessarily reflect the views and policies of the funding agencies, and mention of trade names or commercial products do not constitute endorsement or recommendation for use.

\section{References}

Agrawal A, McSweeney C, Perrin N (2008) Local institutions and climate change adaptation. http://siteresources.worldbank.org/EXTSOCIALDEVELOPMENT/ Resources/244362-1164107274725/3182370-1164201144397/_Local_ Institutions-Climate_Change_Adaptation_note113.pdf. Accessed 10 Jan 2018

Amundsen H, Berglund F, Westskog H (2010) Overcoming barriers to climate change adaptation-a question of multilevel governance? Environ Plan C Gov Policy 28(2):276-289

Babcock M (2013) State Hazard mitigation plans and climate change: rating the States. Columbia Law School Center for Climate Change Law, November. https://web.law.columbia.edu/sites/default/files/microsites/climate-change/ files/Publications/Students/SHMP\%20Survey_Final.pdf. Accessed 10 Jan 2018

Baker I, Peterson A, Brown G, McAlpine C (2012) Local government response to the impacts of climate change: an evaluation of local climate adaptation plans. Landsc Urban Plan 107(2):127-136

Bassett E, Shandas V (2010) Innovation and climate action planning. J Am Plann Assoc 76(4):435-450 
Baynham M, Stevens M (2014) Are we planning effectively for climate change? An evaluation of official community plans in British Columbia. J Environ Plan Manage 57(4):557-587

Berke P, Godschalk D (2009) Searching for the good plan: a meta-analysis of plan quality studies. CPL Bibliogr 23(3):227-240

Berke P, Kaiser EJ (2006) Urban land use planning, 5th edition (April 10, 2006). University of Illinois Press, Champaign

Berke P, Smith G, Lyles W (2012) Planning for resiliency: evaluation of state hazard mitigation plans under the disaster mitigation act. Nat Hazards Rev 13(2):139-149

Berke PR, Lyles W, Smith G (2014) Impacts of federal and state hazard mitigation policies on local land use policy. J Plan Educ Res 34(1):60-76

Berke P, Newman G, Lee J, CombsT Kolosna C, Salvesen D (2015) Evaluation of networks of plans and vulnerability to hazards and climate change: a resilience scorecard. J Am Plan As 81(4):287-302

Bierbaum R, Smith JB, Lee A, Blair M, Carter L, ChapinIII FS, Fleming P, Ruffo S, Ruffo S, Stults M, McNeeley S, Wasley E, Verduzco L (2013) A comprehensive review of climate adaptation in the United States: more than before, but less than needed. Mitig Adapt Strat Global Change 18(3):361-406

Bierbaum R, Lee A, Smith J, Blair M, Carter LM, Chapin FS, Fleming III P, Ruffo S, McNeeley S, Stults M, Verduzco L, Seyller E (2014) Chapter. 28: Adaptation. In: Melillo JM, Richmond Terese TC, Yohe GW (eds) Climate change impacts in the United States: The Third National Climate Assessment, U.S. Global Change Research Program, pp 670-706

Brody SD, Zahran S, Grover H, Vedlitz A (2008) A spatial analysis of local climate change policy in the United States: risk, stress, and opportunity. Landsc Urban Plan 87(1):33-41

EPA (United States Environmental Protection Agency) (2015) Climate Change in the United States: Benefits of Global Action. https://www.epa.gov/sites/ production/files/2015-06/documents/cirareport.pdf. Accessed 10 Jan 2018

FEMA (Federal Emergency Management Agency) (2010) Developing and maintaining emergency operations plans. https://www.fema.gov/medialibrary-data/20130726-1828-25045-0014/cpg_101_comprehensive_ preparedness_guide_developing_and_maintaining_emergency_operations_ plans_2010.pdf. Accessed 10 Jan 2018

FEMA (Federal Emergency Management Agency) (2011a) Local mitigation plan review guide. https://www.fema.gov/media-librarydata/20130726-1809-25045-7498/plan_review_guide_final_9_30_11.pdf. Accessed 10 Jan 2018

FEMA (Federal Emergency Management Agency) (2011b) FEMA climate change adaptation policy statement https://www.fema.gov/media-librarydata/20130726-1919-25045-3330/508_climate_change_policy_statement.pdf. Accessed 10 Jan 2018 
FEMA (Federal Emergency Management Agency) (2013a) Integrating hazard mitigation into local planning. https://www.fema.gov/media-librarydata/20130726-1908-25045-0016/integrating_hazmit.pdf. Accessed 10 Jan 2018

FEMA (Federal Emergency Management Agency) (2013b) Integrating the Local Natural Hazard Mitigation Plan into a Community's Comprehensive Plan. https://www.fema.gov/media-library-data/1388432170894-6f744a8afa892917 1dc62d96da067b9a/FEMA-X-IntegratingLocalMitigation.pdf. Accessed 10 Jan 2018

FEMA (Federal Emergency Management Agency) (2013c) Local mitigation planning handbook. https://www.fema.gov/media-librarydata/20130726-1910-25045-9160/fema_local_mitigation_handbook.pdf. Accessed 10 Jan 2018

Field CB (2012) Managing the risks of extreme events and disasters to advance climate change adaptation: special report of the intergovernmental panel on climate change. Cambridge University Press. https://www.ipcc.ch/pdf/specialreports/srex/SREX_Full_Report.pdf. Accessed 10 Jan 2018

Fu X, Gomaa M, Deng Y, Peng Z (2017) Adaptation planning for sea level rise: a study of US coastal cities. J Environ Plann Manage 60(2):249-265

Gasper R, Blohm A, Ruth M (2011) Social and economic impacts of climate change on the urban environment. Curr Opin Environ Sustain 3(3):150-157

Geneletti D, Zardo L (2016) Ecosystem-based adaptation in cities: an analysis of European urban climate adaptation plans. Land Use Policy 50:38-47

Guyadeen D (2018) Do practicing planners value plan quality? Insights from a survey of planning professionals in Ontario, Canada. J Am Plan As 84(1):21-32

Hamin EM (2011) Integrating adaptation and mitigation in local climate change planning. Climate Change and Land Policies

Horney J, Naimi Al, Lyles W, Simon M, Salvesen D, Berke P (2012) Assessing the relationship between hazard mitigation plan quality and rural status in a cohort of 57 counties from 3 states in the southeastern US. Challenges 3(2):183-193

Horney J, Nguyen M, Salvesen D, Dwyer C, Cooper J, Berke P (2016) Assessing the quality of rural hazard mitigation plans in the southeastern United States. J Plan Educ Res 37(1):56-65

Hu Q, Tang Z, Zhang L, Xu Y, Wu X, Zhang L (2018) Evaluating climate change adaptation efforts on the U.S. 50 States' hazard mitigation plans. Nat Hazards 92:783-804

Krippendorff K (2012) Content analysis: An introduction to its methodology, 3rd edn. Sage, Thousand Oaks

Laukkonen J, Blanco PK, Lenhart J et al (2009) Combining climate change adaptation and mitigation measures at the local level. Habitat Int 33(3):287-292

Lempert RJ, Collins MT (2007) Managing the risk of uncertain threshold responses: comparison of robust, optimum, and precautionary approaches. Risk Anal 27(4):1009-1026 
Lin BB (2011) Resilience in agriculture through crop diversification: adaptive management for environmental change. Bioscience 61(3):183-193

Lyles W, Stevens M (2014) Plan quality evaluation 1994-2012: growth and contributions, limitations, and new directions. J Plan Educ Res 34(4):433-450

Lyles LW, Berke P, Smith G (2014) Do planners matter? Examining factors driving incorporation of land use approaches into hazard mitigation plans. J Environ Plann Manage 57(5):792-811

Measham TG, Preston BL, Smith TF, Brooke C, Gorddard R, Withycombe G, Morrison C (2011) Adapting to climate change through local municipal planning: barriers and challenges. Mitigation Adapt Strat Global Change 16(8):889-909

Moser SC, Luers AL (2008) Managing climate risks in California: the need to engage resource managers for successful adaptation to change. Clim Change 87(1):309-322

Næss LO, Bang G, Eriksen S, Vevatne J (2005) Institutional adaptation to climate change: flood responses at the municipal level in Norway. Global Environ Change 15(2):125-138

Picketts IM, De'ry SJ, Curry JA (2014) Incorporating climate change adaptation into local plans. J Environ Plann Manage 57(7):984-1002

Preston BL, Westaway RM, Yuen EJ (2011) Climate adaptation planning in practice: an evaluation of adaptation plans from three developed nations. Mitigation Adapt Strat Global Change 16(4):407-438

Romsdahl RJ, Atkinson L, Schultz J (2013) Planning for climate change across the US Great Plains: concerns and insights from government decision-makers. J Environ Stud Sci 3(1):1-14

Rumore D, Schenk T, Susskind L (2016) Role-play simulations for climate change adaptation education and engagement. Nat Clim Change 6(8):745-750

Schwab J (2010) Hazard mitigation: Integrating best practices into planning. American Planning Association. Planning Advisory Service, Report Number 560. Chicago, IL

Shi L, Chu E, Debats J (2015) Explaining progress in climate adaptation planning across 156 US municipalities. J Am Plan As 81(3):191-202

Shi L, Chu E, Anguelovski I, Aylett A, Debats J, Goh K, Schenk T, Seto KC, Dodman D, Roberts D, Roberts JT, VanDeveer SD (2016) Roadmap towards justice in urban climate adaptation research. Nat Clim Change 6(2):131-137

Snover AK, Whitely Binder L, Lopez J, Willmott E, Kay J, Howell D, Simmonds J. (2007) Preparing for climate change: a guidebook for local, regional, and state governments. In association with and published by ICLEI - Local Governments for Sustainability, Oakland, CA

Stevens MR, Senbel M (2017) Are municipal land use plans keeping pace with global climate change? Land Use Policy 68:1-14

Stevens MR, Lyles W, Berke PR (2014) Measuring and reporting intercoder reliability in plan quality evaluation research. J Plan Educ Res 34(1):77-93

Stone B, Vargo J, Habeeb D (2012) Managing climate change in cities: will climate action plans work? Landscape Urban Plann 107(3):263-271 
Tang Z, Brody SD, Quinn C, Chang L, Wei T (2010) Moving from agenda to action: evaluating local climate change action plans. J Environ Plann Manage 53(1):41-62

Tang Z, Dai Z, Fu X, Li X (2013) Content analysis for the US coastal states' climate action plans in managing the risks of extreme climate events and disasters. Ocean Coast Manage 80:46-54

Urwin K, Jordan A (2008) Does public policy support or undermine climate change adaptation? Exploring policy interplay across different scales of governance. Global Environ Change 18(1):180-191

USGCRP (2017) Climate science special report: fourth national climate assessment, volume I [Wuebbles DJ, Fahey DW, Hibbard KA, Dokken DJ, Stewart BC, Maycock TK (eds)]. U.S. global change research program, Washington, DC, USA. https://doi.org/10.7930/j0j964j6

Van Aalst MK, Cannon T, Burton I (2008) Community level adaptation to climate change: the potential role of participatory community risk assessment. Global Environ Change 18(1):165-179

Wheeler SM (2008) State and municipal climate change plans: the first generation. J Am Plan As 74(4):481-496

Wisner B (2004) Assessment of capability and vulnerability. Mapping vulnerability: disasters, development and people. Earthscan, London pp 183-193

Woodruff SC, Stults M (2016) Numerous strategies but limited implementation guidance in US local adaptation plans. Nat Clim Change 6:796-802 